386 Fr. Schroeder, Verunreinigung d. officin. rein. Chlorwasserstoffsäure.

wird. Dahingegen eignet sich ein durch Glühen von Gyps mit Kohle dargestelltes Schwefelcalcium sehr gut. Man übergiesse 1 Theil desselben mit 3 Theilen Wasser und füge 3 Theile krystallisirtes Chlormagnesium zu.

Will man Kalium - oder Natriumhydrosulfid verwenden, so sättige man eine Lösung von 1 Theile Aetzkali oder Aetznatron in 3 bis 5 Theilen Wasser mit gewöhnlichem Schwefelwasserstoff, füge das Doppelte des angewandten Kali oder Natron, Bittersalz oder Chlormagnesium hinzu und erwärme gelinde.

\title{
Ueber die Verunreinigung der officinellen reinen Chlorwasserstoffsäure durch organische Chlor- verbindungen.
}

Von Dr. Fr. Sehroeder, Apotheker in Göttingen.

Schon mehrfach hat die Erfahrung gezeigt, dass chemische Präparate, welche den Anforderungen der deutschen Pharmacopöe an ihre Reinheit völlig genügten, dennoch in Folge von in ihnen nicht vorausgesehenen Verunreinigungen für den medicinischen Gebrauch verwerflich waren. $\mathrm{Zu}$ dieser Erscheinung mögen nachfolgende Mittheilungen einen wohl allgemein interessirenden Beitrag liefern. Als "Acid. hydrochloric. purum" erhielt ich in letzter Zeit aus gut renommirten Drogenhandlungen dreimal eine Säure, welche, scheinbar den Anforderungen der Pharmacopöe entsprechend, für den medicinischen Gebrauch verworfen werden musste. Verdüchtig erschien die Säure durch einen auch noch in grosser Verdünnung $(1: 100 !) \mathrm{zu}$ Tage tretenden unangenehmen, etwas fauligen Geruch, wie er bei der Chlorirung organischer Körper, spec. von Kohlenwasserstoffen (Benzol, Toluol etc.) entsteht, und durch einen bei ebenso grosser Verdünnung höchst widerlichen Geschmack, der, ebenso wie der Geruch, zwar an Chlor erinnerte, sich aber von diesem bedeutend unterschied. Die Reaction der Pharmacopöe, Bläuung durch Jodzinkstärkelösung, trat nicht ein, wenigstens erst nach $1 / 2-1$ Stunde in höchst schwacher Weise (bläuliches Schimmern der Flüssigkeit), ein Zusatz einer Spur Jodkalium beschleunigte das Blauwerden dagegen bedeutend, während bei einer Gegenprobe (Mischung einer absolut reinen Salzsäure mit einem Tropfen Chlorwasser) sich dieser Unter- 
schied nicht zeigte. Die sich am raschesten bläuende Säure enthielt noch eine Spur Eisen, welches durch Rhodankalium angezeigt wurde, nicht aber durch die Reaction der Pharmacopöe. Kaliumpermanganat wurde durch jede der drei Säuren in grosser Verdünnung sehr rasch völlig entfärbt, so dass sich die betreffenden organischen Chloride also der chlorigen Säure gleich gegen ersteres verhalten. Reine Chlorwasserstoffsäure entfärbt in verdünnter Lösung bekanntlich Kaliumpermanganat nur sehr langsam. Während nun reines Chlor aus der Chlorwasserstoffsäure leicht zu beseitigen ist, scheinen die organischen Chlorverbindungen in Folge ihres hochliegenden Siedepunkts kaum ganz herauszubringen zu sein, ohne die Darstellung der Säure durch wiederholte fractionirte Destillation sehr zu compliciren. Auf Grund der oben angeführten Eigenschaften derartig verunreinigter Chlorwasserstoffsäure, welche jetzt als Nebenprodukt bei der Farbenfabrikation gewonnen, wahrscheinlich viel in den Handel kommen wird, ist dieselbe, ganz abgesehen von event. Giftigkeit von Chlortoluol etc., entschieden für den medicinischen Gebrauch zu verwerfen.

Schliesslich sei noch bemerkt, dass ich betreffs der einen Säure die zuverlässige Nachricht erhalten habe, dass zur Destillation derselben in der betreffenden Fabrik, wegen temporären Reinwassersmangels, sohlechtes Brunnenwasser genommen ist, so dass also bei dieser Säure die organischen Stoffe auf natürlichem Wege hineingekommen sind, und ist die Möglichkeit nicht ausgeschlossen, dass eine der andern Säuren aus derselben Quelle stammt, wenngleich jede derselben Unterschiede zeigte. Abgesehen nun von generellen, durch einen constanten Darstellungsmodus bedingten Verunreinigungen, können immerhin auch durch eine exceptionelle Verunreinigung bei einer sich in ganz kurzer Zeit auf tausende Kilos belaufenden Fabrikation eines Präparates, wie der reinen Salzsäure, unzählige Unannehmlichkeiten hervorgerufen werden.

\section{B. Monatsbericht.}

\section{Nahrungs- und Genussmittel, Gesundheitspflege.}

F. Renk stellte in Anschluss an die Versuche von Pettenk of er über electrisehe Beleuohtung und Luftbeschaffenheit (vgl. Archiv 84, S. 379), Beobachtungen an über die electrische Beleuchtung des Kgl. Hof , und 